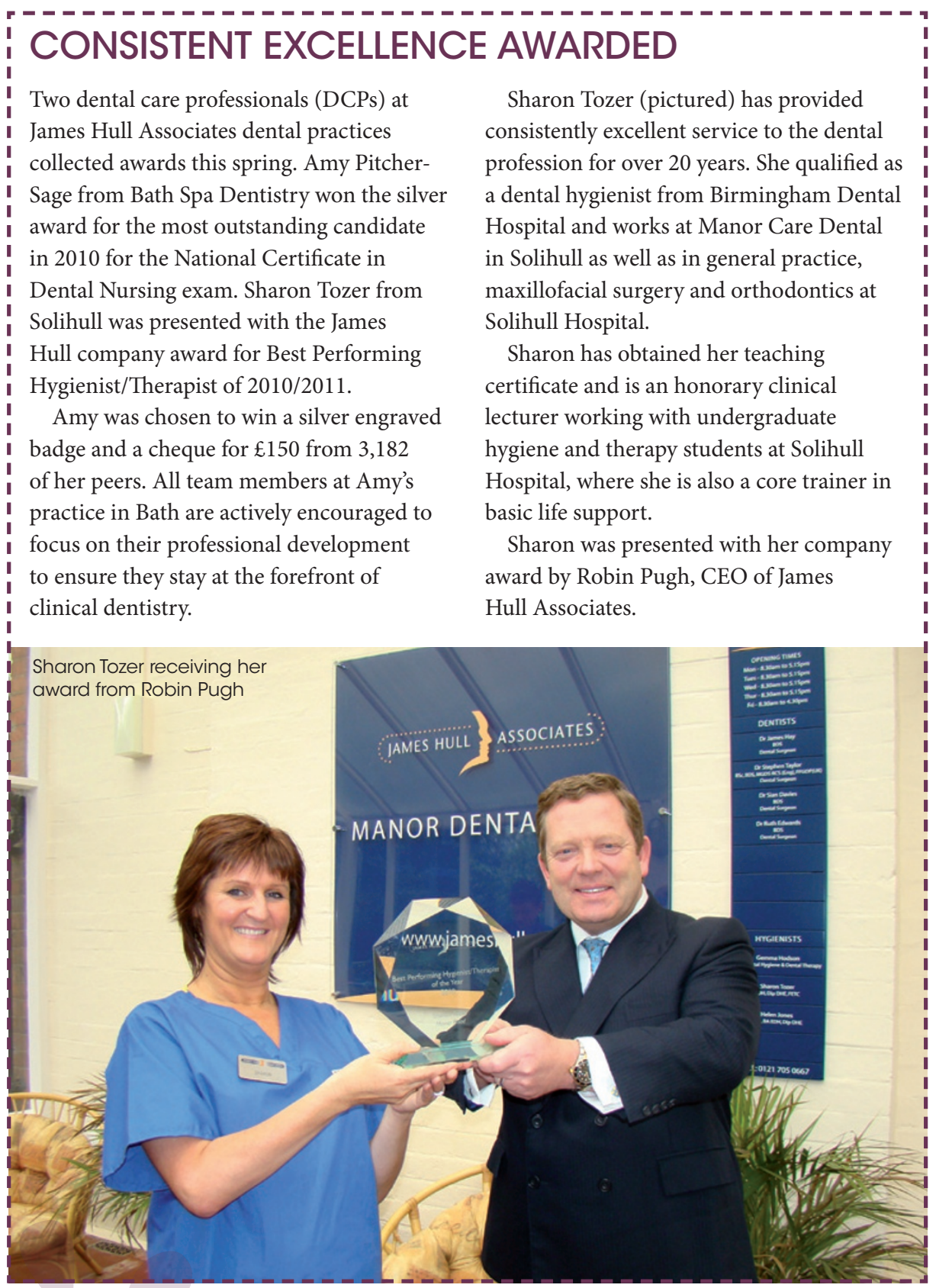

\section{NEBDN EXAMINERS NEEDED}

The National Examining Board for Dental Nurses (NEBDN) is seeking to recruit new members to its Panel of Examiners in order to deliver a new assessment of the National Certificate in Dental Nursing qualification in 2011

Featuring Objective Structured Clinical Examinations (OSCEs), NEBDN has completely revised the format of the qualification in order to provide a more modern approach to the assessment of dental nurses.

To become an Examiner with NEBDN you must: have previous experience of assessing OSCEs within dental training; be registered with the General Dental Council (GDC); be currently practising as a dental surgeon or dental care professional (DCP); have two years' experience since qualification; be well organised and able to maintain high quality standards; and be passionate about dental nurse education and helping people reach their full potential.

Becoming an examiner will help you to: improve your personal development and professional status; develop your skills and understanding of dental nurse education and training; gain verifiable CPD through ongoing support and training; and network with other professionals with a commitment to improving dental nurse education.

For further information and an application pack visit wwww.nebdn.org or email sarah@ nebdn.org.

\section{GIVE PAIN RELIEF IN THE PUNJAB}

The Rotary Clubs of Mill Hill in London and Sirhind in the Punjab, India are calling for volunteer dental professionals for the Pain Relief Dental Clinic which they helped establish in Hansali, India.

Hansali is a small village in the heart of rural Punjab, North West India and home to 220 people. Access to any type of medical care, including dental treatment, is unaffordable or inaccessible to villagers. The Pain Relief clinic was set up in February 2009 and serves as a primary care facility available free of charge to the local community. With three permanent staff, the clinic has treated over 80,000 patients in the last 12 years.

Visiting volunteer dental professionals stay at the clinic for periods from one week to one month treat patients and share their experience and technical expertise with the local staff. Most visitors pay their own way although air-conditioned accommodation and vegetarian food are provided.

If any dentists, dental nurses or dental hygienists are interested in volunteering at the clinic, email Mr Coonar on hscoonar@ hotmail.com or telephone 02084401860 . 